\title{
The effect of altitude and slope on the spatial patterning of burglary
}

\author{
G. D. BREETZKE
}

\begin{abstract}
Physical geography is significant for crime, and its presence or absence, yet no studies have investigated the relationship between crime and certain broader features of physical geography such as altitude, and slope. In this study I attempt to fill this gap by using OLS and geographically weighted regression to gauge the effect of altitude and slope on burglary patterns in Tshwane, South Africa. In the analysis I found considerable evidence that residing at a greater altitude reduces your risk of burglary victimization, although residing on steeper slopes had no effect. In the discussion I argue that the underlying relief and terrain on which neighborhoods are built should form an essential 'physical' component of the environmental backcloth that surrounds offenders and influences their spatial decision making processes.
\end{abstract}

\section{Keywords}

Burglary, altitude, slope, topography, South Africa 


\section{The effect of altitude and slope on the spatial patterning of burglary}

\section{Introduction}

It is widely acknowledged that crime is a geographic phenomenon. Every incident of crime can be spatially referenced and subsequently mapped and analyzed using a range of geostatistical and geospatial tools. Two physical geography features of every crime incident location that have been largely ignored by researchers up until now have been the altitude and slope at which crime occurs. In fact there has not been a single study anywhere that has empirically investigated the relationship between crime, and these two fundamental features of physical geography. This study aims to fill that gap by examining the effect that altitude and slope play in the perpetration of burglary. A case study approach was used to examine burglary incidences committed in Tshwane, South Africa from 2003-2006.

Anecdotal evidence suggests that the physical lay of the land on which cities are built can facilitate or impede crime. Felson (2002), for example, suggests that the long, sloping hills of San Francisco have not prevented high crime rates in the city, but the choppy hills of Pittsburgh have kept its crime rates relatively low for a number of decades. In Los Angeles, Felson notes that crimes rates appear to be high in the flatlands but low in urban villages at the edge of mountains. These observations notwithstanding, there has been no empirical examination as to whether residing at a greater altitude or on a steeper slope increases or reduces your risk of victimization of any type of crime. Other features of physical geography and their relationship with crime and disorder have been the subject of investigations by researchers for well over a century. For example, a large and growing body of literature has investigated the relationship between weather and crime (see Baumer \& Wright, 1996; Brunsdon, Corcoran, Higgs, \& Ware, 2009; Ceccato, 2005; Cohn \& Rotton, 2000; Heller \& 
Markland, 1970). Despite some contradictions, researchers have found that crime rates generally display a seasonal pattern with property crimes typically peaking in winter, and crimes against the person peaking in the hot months of summer (Landau \& Fridman, 1993; Van Koppen \& Jansen, 1999). In addition to temperature variations, researchers have found how crime rates vary dependent on a range of other meteorological parameters including rainfall patterns (Perry \& Simpson, 1987), sunlight hours (Heller \& Markland, 1970), atmospheric pressure (Feldman \& Jarmon, 1979) and humidity and windspeed (Rotton \& Frey, 1985). The influence of water bodies on the spatial distribution of crime has also been investigated. In the majority of these studies researchers have examined how waterbodies such as rivers, canals and estuaries act as physical barriers that impact an offenders' macrolevel location choice. For example, Peeters and Elffers (2010) found that the presence of canals in The Hague, The Netherlands, had little effect on crime trips by offenders while Clare, Fernandez, and Morgan (2009) found that the Swan river estuary in Perth, Australia decreased the likelihood of selection of certain areas for burglary. Other theoretical and empirical work on this topic includes Brantingham and Brantingham (2000; 2003) and Felson (2002). In terms of vegetation, Ratcliffe (2003) found no effect on grass, bushes and trees as urban barriers on burglary patterns in Canberra, Australia but in Chicago Kuo and Sullivan (2001) found dramatically fewer occurrences of crime against both people and property in apartment buildings surrounded by trees and greenery than in nearby identical apartments that were surrounded by barren land. Whilst these studies have helped scholars gain a better understanding of what guides offender movements and motivates area target selections it is largely unclear how the altitude and slope of an area influences an offender's movements in general and a burglar's movements in particular. This is certainly surprising especially when one considers current theoretical explanations of burglary and place (see Bernasco \& Luykx, 2003; Hammond \& Youngs, 2011) as well as how physical geography settings are the central 
organizing feature of crime and its absence (Felson, 2002). One reason provided for the lack of incorporation of altitude and slope in crime research is the social science origins of criminology (Felson, 2002), while another reason could be the common conception in current criminological literature that distance and direction are more important determinants in the selection of a suitable target area for a burglar than other more physical geography features of the urban environment (see Hammond \& Youngs, 2011). Regardless of the reasons provided there can be little doubt that physical geography as a discipline is significant for crime and that more in depth analysis is required to tease out the exact nature of the association between certain overlooked features of physical geography and their relationship with criminal behavior.

\section{Theoretical application}

One of the earliest theoretical explanations of crime and place is the social disorganization theory of Shaw and McKay (1942). Under this theoretical approach, crime is more prevalent in geographic areas that exhibit social and physical incivilities. In these areas levels of social control is low due to a breakdown in institutions such as the family and school. For social order to exist, a sense of community or community cohesion should prevail which allowed the community to uphold common goals and regulate itself through formal and informal measures (Jacob, 2006). It was however the emergence of environmental criminology in the 1980s that 'formalized' the important role of place in criminological literature. In their seminal work Environmental Criminology, Patricia and Paul Brantingham (1981) suggested that any crime comprised four dimensions: the law, the offenders, the target, and the place. Importantly, the place is not simply a spatial location but is a setting in space and time at which the other three dimensions of crime intersect and a criminal event occurs. Three major theoretical perspectives are housed within the school of environmental criminology: crime 
pattern theory, rational choice theory, and routine activities theory. Crime pattern theory explores the distribution and interaction of targets, offenders, and opportunities across time and space (Brantingham \& Brantingham, 1991). According to crime pattern theory offences are most likely to occur where opportunity spaces - places perceived by the offender to contain attractive targets - intersect with awareness spaces - places about which an offender has specific environmental knowledge, for example the surroundings of his or her home. Importantly, an individuals' awareness spaces do not exist in isolation but are made up of different structures which provide opportunities to commit crime depending on the environmental backcloth - the social, psychological, physical and temporal mosaic of the offender passing through space (Chainey \& Ratcliffe, 2005). The rational choice approach advances a perspective of crime that considers the situational context in which criminal events transpire (Cornish \& Clarke, 1986). This perspective posits that offenders interpret and weigh up the costs and benefits associated with their offending decisions. With respect to burglary the idea is that burglars will attempt to maximize the rewards of a burglary by purposefully and carefully selecting a target from a range of alternates. The routine activities (RA) approach provides a simple yet attractive insight into the causes of criminal behavior. Within this now well-known framework crime occurs when there is a convergence in space and time of three minimal elements: a motivated offender, a suitable target and the lack of a capable guardian (Cohen \& Felson, 1979). The RA theory postulates that changes in routine or typical activities increase the probability that individuals or households will be vulnerable to certain types of criminal victimization.

In the present study I focus on the RA theory and hypothesize that the altitude and slope of an area will influence one element in the RA framework, namely the selection of a suitable target. More specifically, I hypothesize that a neighborhood located at a greater altitude or on a steeper slope is less likely to be selected for burglary than a neighborhood located at lower 
altitudes or on a flatter slope. With respect to burglary, Bernasco and Luykx (2003) highlight the roles of target attractiveness, opportunity and accessibility in the location of a suitable target. Target attractiveness, in this instance, refers to the prospective profitability of a burglary if it is successful. There have been considerable theoretical advances made in understanding what makes a suitable target attractive. At the household-level studies have found that households with higher income (Vélez, 2001; Zhang, Messner, \& Liu, 2007), and with fewer safety features (Bowers, Johnson, \& Hirschfield, 2004) have a greater risk of victimization. Neighborhood-level victimization studies have found that more affluent households (Vélez, 2001); and households with a greater number of household appliances (Sampson \& Wooldredge, 1987) increase burglary risk. Lastly, multilevel research has found that individuals residing in disadvantaged neighborhoods have higher risks of victimization than do individuals living in less disadvantaged neighborhoods (see Sampson \& Wooldredge, 1987; Miethe \& Meier, 1994).

Opportunity refers to the likelihood of successful completion of a burglary. Brown and Altman (1981) suggest that neighborhoods characterized by unstable and non-cohesive social structures provide better opportunities for burglars. The idea is that the anonymity in these neighborhoods makes it less likely for a resident or bystander to intervene should they see or hear something suspicious. Researchers assessing the effects of opportunity on burglary rates have typically used variables such as residential mobility and ethnic heterogeneity to represent the lack of social cohesion and collective efficacy within neighborhoods (see Bernasco \& Luykx, 2003; Sampson \& Groves, 1989). The results of this research indicate that the more mobile and heterogeneous a neighborhood is the higher the risk of burglary. Of course, the relationship between target attractiveness and opportunity is mediated by the target's accessibility. The more accessible an area is in terms of its social and physical infrastructure, the more likely it is to be suitable and selectable as a target. Armitage (2007) 
for example, found that homes located on main roads with greater accessibility were at a greater risk for burglary while Johnson and Bowers (2010) found that the more permeable a street network was the greater the burglary risk in an area. The risk of burglary was also found to be higher on more major roads and on those street segments that are connected to major roads.

Related to the concept of target accessibility is the principle of least effort (see Zipf, 1949) in the selection of a suitable target. The least effort principle at its most fundamental level suggests that given two alternatives to a course of action, a person will choose one that requires the least effort - that is; people will adopt the easiest course of action (Turvey, 2008). Within a crime context, the principle of least effort suggests that burglars will exert the minimum effort possible in order to complete a burglary. The geographic expression of the principle of least effort is distance decay, which suggests a spatial pattern of criminal activity whereby most crimes are committed nearer rather than farther from the criminals' own homes (van Koppen \& de Keijser, 1997). Not surprisingly, the notion that motivated offenders 'diffuse' from where they live in order to commit crime in their awareness and activity space (presumably between their residence, place of work, and place of recreation) has generated a great deal of research, with varying results (see Bichler, Christie-Merrall, \& Sechrest, 2011; Rengert, Piquero, \& Jones, 1999; Snook, 2004). It is within this awareness space however, that an offender will select a suitable target and that is where the physical geography of an area is likely to play a role. In short, the main question to be answered in this study is the following: Does the location of a neighborhood at a greater altitude or on a steeper slope increase or decrease its suitability for selection for burglary?

This question is answered by initially providing descriptive space-time indicators for day time and night time burglary patterns in Tshwane by altitude and slope. Using routine activities theory as a theoretical backcloth I next construct models for day time and night time 
burglary patterns using OLS and geographically weighted regression analysis. Burglary rates were separated into day/night rates since previous research has shown how burglars change their targeting strategies depending on whether it is day time or night time (see Coupe \& Blake, 2006).

\section{The geography of Tshwane, South Africa}

As a geographical focus area, the area under consideration is the city of Tshwane located in the central Gauteng province of South Africa. Tshwane is the capital city of South Africa and has an estimated residential population of approximately two million people. In terms of its urban structure the city consists of formerly whites-only neighborhoods around an increasingly Black African ${ }^{1}$ central business district. The former apartheid townships ${ }^{2}$ of Atteridgeville (Black African) and Laudium (Indian) lie on the western edge of the city and the townships of Eersterus (Colored) and Mamelodi (Black African) lie on the eastern edge. The pre-apartheid urban structure in Tshwane has been largely retained except for the almost complete replacement of whites by Black Africans in large parts of the inner city; the expansion of Black African townships with informal housing; and the establishment of a few informal settlements amidst previously whites-only neighborhoods. In terms of its physical geography, Tshwane lies at an altitude of between 1100-1700 meters above mean sea level in a sheltered valley surrounded by the Magliesberg mountain range. Its undulating topography makes Tshwane ideally suited to examine the effect of these two physical geography features on the spatial patterning of burglary.

\footnotetext{
${ }^{1}$ The South African population is still officially classified into racial groups. 'Black Africans' represent the descendants of west and central African populations. The 'Indian' population group represent the descendents of south Asian populations. The 'Colored' group comprise a mixed population including the descendents of the indigenous Khoisan population, imported Malay slaves, and people born out of mixed-race relations.

2 'Township' refers to built-up residential areas (neighbourhoods) that are still dominantly (+95,0\%) inhabited by black people. Under the apartheid policy focusing on separate development, these areas were originally reserved for black people only.
} 


\section{Material and methods}

\subsection{Data}

The data used to measure burglary in Tshwane was obtained from the Crime and Information Analysis Centre of the South African Police Services (SAPS). The information obtained included the location ( $\mathrm{x}, \mathrm{y}$ co-ordinate), date, time of day and unique code for each burglary incident for the years 2003-2006. Using police data to measure crime has well-known limitations, particularly in South Africa (see Herbert \& Harries, 1986; Breetzke, 2006). Despite this however previous research has shown that using official police data usually produces results consistent with victimization surveys (see Byrne \& Sampson, 1986; McDowall \& Loftin, 1992; Ceccato \& Dolmen, 2011). In any event official records from the SAPS represent the only official and spatially replete crime dataset available in the country. Whilst request for police service data may provide a better measure of burglary activity over this period this information is currently unavailable in South Africa. A total of 256,032 incidences of burglary were recorded in Tshwane over this three-year period ( $M$ per suburb per year $=177.85 ; S D$ per suburb per year $=357.86)$. More burglaries were committed during the day (total 141,$121 ; M$ per suburb per year $=98 ; S D$ per suburb per year $=238.30$ ) than during than night (total 114,$911 ; M$ per suburb per year $=79.85 ; S D$ per suburb per year $=$ 133.42). Other data for this project was obtained from the Statistics South Africa census dataset for 2001. Both the crime and census data were aggregated to the suburb level. The suburb is the finest spatial level at which census information has been provided by Statistics South Africa and consists of between 150 - 300 households. All 371 suburbs in Tshwane were initially selected as possible locations for the burglaries examined in the study but 11 suburbs were excluded in the final analysis because they contained no households. These suburbs were either nature reserves, or areas of vacant land. 


\subsection{Dependent variable}

The numbers of day time and night time burglary incidents per 100 households reported to the SAPS were the dependent variables in the study. Not surprisingly, initial checks on both burglary rates showed highly skewed distributions and evidence of kurtosis. In order to remove this non-normality both dependent variables were log transformed. The transformation of the burglary rates was an important step in the analysis since non-normally distributed variables can distort relationships and significance tests generated in the results.

\subsection{Independent variables}

The selection of independent variables in the study was guided by the routine activities framework. Variables that typically reflect the routine activities approach include population characteristics, employment status, income levels and dwelling values. Given the census data at my disposal I sought to operationalize routine activities concepts as best I could.

The measures of motivated offenders in the analysis include the percentage unemployed, percentage males aged between 15-34, and a Services Deprivation Index (SDI). The latter is a multidimensional deprivation index based on the United Nations Development Program's (2003) parameters for deprivation in each of five dimensions: type of dwelling, source of water, toilet facilities, refuse or rubbish removal, and energy or fuel for lighting, heating or cooking. An index was created for each of the five dimensions to measure the relative deprivation of each parameter per suburb in Tshwane. The deprivation index was then calculated as a simple average of the five basic services indexes, with 0 indicating extreme deprivation and 1 indicating affluence. All three variables selected to reflect the 'motivated 
offenders' measure in RA theory have previously been shown to increase offender motivation in Tshwane (see Breetzke, 2006; Breetzke \& Horn, 2009).

Two variables were used to capture the measure of guardianship. First, population density which is measured as the number of people per kilometer squared. An increase in population density is expected to have a positive relationship to burglary given that population density can be seen as a surrogate for the distribution of private property, much of which offers attractive targets to burglars (Harries, 2006). Second, a dummy variable equal to one is used to indicate whether a suburb is fully or partially enclosed in a gated community. A total of 43 of the 360 suburbs (12\%) of Tshwane utilized in this study are either entirely or partially gated. Whilst this is a small percentage it was considered important to include this measure in the analysis since gated suburbs could be considered as being capable guardians against burglary. Indeed, in South Africa gated suburbs have only one central access point which is strictly controlled; the suburbs themselves are also bounded by electric fencing and are patrolled by a series of armed guards. Gated communities or 'closed neighborhoods' have experienced phenomenal growth in South Africa since the 1990s (Landman \& Schönteich, 2002) borne out of the general public's assertion that the South African government, and concomitantly the SAPS are unable to adequately protect its citizens post-apartheid.

Measures of suitable targets include mean altitude, mean slope, road density, mean household income, and proximity to potential burglars. The mean altitude and mean slope for each suburb were calculated from a high resolution digital elevation model that was constructed for Tshwane using Light Detection and Ranging (LiDAR) data and overlain onto the suburban vector dataset. A potential limitation of the use of these measures of mean slope and mean altitude in the study area is the spatial heterogeneity of these features within suburbs. I would argue however that as continuous phenomena, both altitude and slope are less prone to the deleterious effects of within-unit variability than say, unemployment or 
population density. Besides, I am weary of adhering to levels of detail that make identifying general patterns of association between burglary and the selected RA concepts difficult to identify.

Road density is defined as the total length of streets in a neighborhood (in meters) divided by the total land area measured in square kilometres. Previous research has shown how the more dense and accessible a suburb is in terms of its street network the more likely it is to be suitable and selectable as a target for burglary (see Armitage, 2007; Johnson \& Bowers, 2010). The mean household income of a suburb should increase the suitability of potential targets as the greater the household income presumably the more desirable and valuable are the household contents. Some prior research has provided evidence for this relationship (Miethe \& Meier, 1990; Rice \& Smith, 2002).

Recent research has shown how the likelihood of a suburb being selected for burglary is heightened by its proximity to where offenders live (see Bernasco \& Nieuwbeerta, 2005; Bichler et al., 2011). If a suburb is relatively close to numerous potential offenders, then that suburb would be more suitable for selection as a target than a suburb located further away. As a result a measure of proximity to potential burglars was calculated for each suburb in Tshwane. This was done using the method of Breetzke and Horn (2009) who constructed an offender risk profiling system for Tshwane based on the geodemographic profile of 1870 existing offenders. In their study the 371 suburbs of Tshwane were classified from high to low risk for offender development on the basis of a number of ecological risk factors. Suburbs classified as high-risk for offender development were mainly characteristic of the Black African townships and distinct socio-demographic factors were associated with these high-risk clusters including a low socio-economic status, low income, and a disrupted family. In the current study a population-weighted centroid for each suburb was created and the mean distance from this centroid to the ten nearest 'high risk' suburb centroids was used as a 
measure of suburb proximity to potential burglars. Although ten seems somewhat arbitrary, models based on 20 and 30 were examined, with similar results. Of course, this measure is a proxy of a complex and multidimensional 'diffusion' process, and it could be that other measures such as that proposed by Bernasco and Luykx (2003) could be more useful. Unfortunately, police and corrections datasets available in South Africa do not contain detailed data of offenders' addresses or physical movements of offenders which restrict the construction of more detailed indices to represent this measure. Descriptive statistics and bivariate correlations for the independent variables are shown in Tables 1 and 2.

[INSERT TABLES 1 and 2 HERE]

\subsection{Modelling framework}

Initially an OLS model was run on the data and tests for autocorrelation in the model's residuals were conducted. Spatial autocorrelation was not found to be present in either of the model's residuals (see Table 3). A check on another OLS diagnostic - the Koenker test however indicated that a geographically weighted regression (GWR) would most likely improve the models results. The Koenker tests whether relationships between some or all of the independent variables and the dependent variable/s is non-stationary. This means, for example, that unemployment may be an important predictor of burglary in some locations in Tshwane, but perhaps a weak predictor in other locations. Unlike OLS and spatial regression, in GWR the relationships between the independent and dependent variables are not assumed to be the same at all locations ( $\mathrm{GaO} \& \mathrm{Li}, 2011)$. One of the common problems with estimating global regression models, like OLS and spatial regression, for spatial data are that 
variations over space that might exist in the data are suppressed (Cahill \& Mulligan, 2007). In contrast, GWR searches the data for systematic spatial regularities while attempting to preserve and model the complexity that nonrandomly diverges from average global patterns (Graif \& Sampson, 2009).

The GWR model can be expressed as:

$$
y_{i}=\beta_{o i}\left(u_{i}, v_{i}\right)+\sum_{n=1}^{k} \beta_{n i}\left(u_{i}, v_{i}\right) x_{n i}+\varepsilon_{i}
$$

where $y_{i}$ is the burglary rate for suburb $i,\left(u_{i}, v_{i}\right)$ denotes the coordinates of the centroid of suburb $i, \beta_{o i}$ and $\beta_{n i}$ represents the local estimated intercept and effect of variable $n$ for suburb $i$, respectively. To calibrate this formula, the bi-square weighting kernel function was used (Brunsdon, Fotheringham, \& Charlton, 1998). The suburbs near to $i$ have a stronger influence in the estimation of $\beta_{n i}\left(u_{i}, v_{i}\right)$ than those located further from $i$. Using this model a localized parameter can be obtained for any location and a thematic map can be created of parameter values. The Akaike Information Criterion (AIC) was used to compare OLS with GWR. This comparison will indicate whether the spatial perspective significantly improves the model fit. Lastly, I used the Monte Carlo approach to test for spatial non-stationarity. The Monte-Carlo method tests if the observed variation in a parameter is sufficient to reject the null hypothesis of a globally fixed parameter (Graif \& Sampson, 2009). Both OLS and GWR models were implemented using GWR 3.0 software. 


\section{Results}

\subsection{Descriptive results}

The first descriptive analysis involved calculating the percentage of burglaries in each altitude band in Tshwane, divided arbitrarily into 100 meter intervals (Fig. 1). The highest point in Tshwane is approximately $1674 \mathrm{~m}$, while the lowest altitude is $1033 \mathrm{~m}$. The percentage of burglary incidences was found to be the highest between altitudes $1300-1400 \mathrm{~m}$, with percentages tapering off at both lower and greater altitudes. This trend was observed for burglaries committed both during the day and during the night. Overall, the mean altitude of all burglaries committed in Tshwane was $1338.84 \mathrm{~m}$, with the day mean $(1340.09 \mathrm{~m})$ only fractionally higher than the night mean $(1337.28 \mathrm{~m})$. The relationship between the percentage of all burglary incidences and the percentage land mass of the study area is shown in Fig. 2 . Almost $45 \%$ of burglary incidences in Tshwane occur between altitudes 1300-1400m, although this altitude band constitutes only $20 \%$ of the land area of the city. In comparison, only $5 \%$ of burglary incidents occur between altitudes $1100-1200 \mathrm{~m}$ yet approximately a fifth of the land area of Tshwane lies within this altitude range.

Fig. 3 shows the percentage of all burglary incidences by quartiles of slope. There is no discernable difference between the percentages of burglary incidences by slope quartile. Burglary is certainly more prevalent on the steeper slopes but there is no clear linear gradient from flat to steep evident in the data. Again, no major differences were detected between burglaries committed during the day and burglaries committed during the night although there are almost 5\% more burglaries during the day at steeper slopes. Of course, there are many other factors that could be used to explain the patterns shown in Figures 1-3 including population density and deprivation, to name a few. These and other factors were controlled for in the regression analyses. 
[INSERT FIGURES 1-3 HERE]

\subsection{Inferential results}

The first baseline OLS model examined the relationship between day time (07:00am$18: 59 \mathrm{pm}$ ) burglaries and measures of routine activities while the second baseline OLS model examined the relationship between night time (19:00pm-06:59am) burglaries and the same measures. The results of both baseline regression models are presented in Table 3 (columns 1 and 3). Both measures of guardianship - population density and gated communities - were significantly and positively related to both day time and night time burglary rates in Tshwane. Burglary rates were found to be higher in partially or fully gated suburbs and in suburbs with a high population density. One reason why burglary was found to be higher in gated communities could be that more affluent residents typically reside in these suburban enclaves in Tshwane and it could be that burglars target these suburbs on the presumption that they will get more profitable rewards for their efforts, despite the difficulty in gaining access. This explanation is supported by previous South African research into property crime (see Schönteich \& Louw, 2001; Zinn, 2008). Of greater concern however is the fact that residing in a gated community in Tshwane does not reduce your risk of burglary victimization.

Research examining the role of population density in predicting crime rates has produced mixed results with some researchers finding a significantly negative relationship between population density and crime patterns (Cahill \& Mulligan, 2003; Cahill \& Mulligan, 2007) while others have found a significantly positive relationship (Byrne \& Sampson, 1986; Dahlbäck, 1998). These mixed results reflect the fact that while population density can increase the number of potential offenders (and targets) in an area; it can also increase the amount of capable guardians against crime. The results of this research however support the classic argument that a high population density offers opportunities for property crimes. 
Interestingly, road density was not found to be significant in either model. This finding contrasts with international literature which has generally found a positive relationship between the permeability of transport networks and burglary (see Armitage, 2007; Johnson \& Bowers, 2010). A possible explanation for this finding could be found in the socio-spatial structure of South African cities. Indeed, the fragmented nature of Tshwane, borne out of the inefficiency of apartheid-style planning, has resulted in the skewed provision of transport infrastructure in the city, often drawn out along racial divides. In the case of Tshwane, the mostly densely populated regions of the city generally have the lowest level of accessibility, connectivity and permeability within the available transport networks (National Spatial Development Perspective, 2006). These densely populated regions are most often poor Black African townships located on the periphery of the city. In contrast, former whites-only neighborhoods in Tshwane have the highest levels of road density and connectivity. The fact that property crime in Tshwane is spatially concentrated in the poorer Black African neighborhoods despite their low level of street network permeability could potentially explain this finding. Future research might focus more specifically on how apartheid's urban spatiality - in terms of its transport infrastructure inequality - may have contributed to the spatial concentration of crime in certain regions of the city. Burglary rates were also found to be high in suburbs characterized by relatively high unemployment. This is in line with the interpretation of unemployment being a measure of offender motivation. Both baseline models exhibit a moderately weak fit to the burglary data $\left(R^{2}\right.$ adjusted for degrees of freedom is .185 for day time burglary and .213 for night time burglary). Inspection of the variance inflation factors showed no evidence of multicollinearity in either model.

[INSERT TABLE 3 HERE] 
The mean altitude and mean slope variables are added to the baseline equations in columns 2 and 4 of Table 3 for day time and night time burglary respectfully. After controlling for the routine activities variables, the mean altitude of a suburb was found to have a weak but negatively significant effect on burglary rates $(\beta=-.004$ and -.003 in the day time and night time models respectively; significant at $p<.05)$. This finding provides the first empirical clue that residing at a greater altitude may reduce your risk of victimization for some types of crime. The inclusion of the mean slope variable was not found to be significant. The addition of both these measures improved the model fit for both day time and night time burglary rates albeit slightly. Whilst the OLS models presented here are of value they provide a single model result or global fit to the data. GWR is preferred in this instance since this approach incorporates important spatial relationships in its makeup and consequently increases the explanatory power of both models. Moreover, the GWR results facilitate the identification of areas where, for example, the altitude of an area plays a more important role in burglary incidents than in other areas.

The same independent and dependent variables used in the OLS models were again used to develop the GWR models. The decreased AIC index and increased adjusted $R^{2}$ statistics indicate that the local GWR model provides a better fit than the global OLS model (see Table 4). Whereas the global $R^{2}$ was .190 and .220 for the day time night time models respectively, the average local $R^{2}$ increased to .330 and .361 for both models. Not surprisingly, the MonteCarlo tests revealed that the relationships between burglary and seven of the ten independent variables displayed significant spatial variation at the 5 percent level across Tshwane for both models. Included in these seven measures are the percent unemployed, the deprivation index, population density, gated communities, and mean altitude. There are a number of ways in which the results of GWR can be displayed graphically (see Huang \& Leung, 2002; and Lee, 2004 for examples). In the current study I provide the t-value maps for the GWR local 
parameters of mean altitude for both day and night time burglary as well as the DEM for Tshwane (see Fig. 4; maps for the other six significant variables are not included due to space considerations and because the focus of this study is to examine the effect of altitude and slope on burglary). A t-value map of a coefficient is broadly similar to the map of the same raw coefficient, but it can reveal interesting spatial variations that would be otherwise missed if I relied solely on the global analysis of raw parameters. The lighter colors in Fig. 4 indicate areas of statistically significant negative values, while the darker colors indicate areas of statistically significant positive values. The resultant t-value maps show that the highly significant positive values are mainly clustered in the north-western region of the city, while the highly significant negative values are predominantly located in the south-western region of Tshwane. As evident from the DEM, the altitude of Tshwane generally increases from north to south. These findings suggest that for both models, the variable appears to have the greatest negative influence on burglary rates at greater altitudes.

[INSERT TABLE 4 and FIGURE 4 HERE]

\section{Discussion}

The aim of this study was to examine the role that two often overlooked physical geography features play in the perpetration of burglary. Whilst I make no definitive claims here, the results of this research do indicate that the altitude of an area can affect the spatial patterning of burglary, both during the day time and during the night time. Suburbs at greater altitudes in Tshwane were consistently found to have lower burglary rates even after controlling for a number of potential confounders in the analysis. The use of GWR provided significant local insight into the global results generated by the OLS regression by revealing significant spatial 
variation in the affect of altitude in predicting burglary. Indeed, areas of greater altitude in the south-western region of the city had significantly negative parameter estimates whilst a smaller number of suburbs of lower altitude had positive parameter estimates. Other GWR results improved the OLS findings.

A discussion of potential mechanisms explaining these results is speculative at this point but a possible explanation could be found in the way in which offenders perceive and interpret their physical geography surroundings. Historically researchers across a range of disciplines have been interested in the way in which humans perceive their physical environment (Edney, 1972; Martino, 2008; Wyant, 2008). Renowned philosopher Immanuel Kant argued that geographical space and its variation can serve as a mental framework for the coordination of an individual's experiences and behavior (Richards, 1974). Based on this notion and borrowing from psychological learning theory, an individual develops cognitive maps of his or her physical environment based on their knowledge and awareness of space, akin (in part) to the awareness space concept espoused in crime pattern theory (Brantingham \& Brantingham, 1991). This cognitive or mental map can then serve as a guide to subsequent movement and behavior. Of course, broader features of physical geography such as altitude can shape an individual's cognitive map and it could be that the way in which a burglar perceives the physical lay of the land within their awareness space could influence their selection of a suitable target. In the context of this study it could be that potential burglars perceive suburbs and residences located at greater altitudes as being more exposed and visible (accessibility) and represent a greater overall risk to the burglar (opportunity) despite being perhaps more profitable (attractive). Previous studies have shown how humans perceive their physical geography surroundings as being 'steeper' and 'higher' than in fact they actually are (see Proffitt, Bhalla, Gossweiler, \& Midgett, 1995; Stefanucci, Proffitt, Clore, \& Parekh, 2008). Within their awareness space, burglars could possibly perceive a 
suburb as being at an altitude greater than it actually is making the suburb appear even more intimidating. Fear further influences human thoughts and behaviors; with researchers showing that fear not only influences the perception of heights and their magnitude but also behavior in height environments (see Stefanucci \& Proffitt, 2009). Of course, there is no greater fear among burglars than the fear of being caught.

The non-significant finding for the association between the mean slope of a neighborhood and burglary was unexpected. Again, explanations for this lack of association are speculative but one possible reason could be related to the heterogeneity in slope within neighborhoods. It could be that the slopes in neighborhoods vary more greatly than other physical geography features like altitude and this within-unit spatial heterogeneity could possibly result in complexities in the interpretation of this variable in the model. Future studies may aim to construct other measures of altitude and slope per neighborhood and include these measures in future crime models. Other measures could include calculating the altitude or slope range per neighborhood; or obtaining the altitude or slope value at the population-weighted centroid of each neighborhood.

In their dissection of the spatial-criminal landscape Patricia and Paul Brantingham (1993: p. 6) urge researchers to "see both the trees and the forest" when investigating crime and criminal events. Whilst a narrow focus to crime research is essential, the Brantinghams motivate that a focus exploring how offenders see, react, and interpret their broader physical surroundings is vital to understanding offender spatial decision making. The results of this study suggest that the broader topography of an area should form an essential 'physical' component of the environmental backcloth that encompass an offender and influences his or her location choice.

Within the RA framework, the results of this research suggest that physical geography features like altitude - and potentially others - can play an important role in understanding 
what makes a target suitable for a burglar. Another way of interpreting these results could be that by reducing your risk of burglary victimization, altitude can act as a capable guardian. At a very general level capable guardians can be defined as all formal or informal control mechanisms that are effective in deterring a motivated offender from committing a criminal act (Cohen \& Felson, 1979). With respect to burglary, guardianship has been differentiated into social and physical domains (Meier \& Miethe, 1993; Garofalo \& Clark, 1992). Social guardianship derives from the surveillance activities of people whilst physical guardianship refers to devices that offer protection such as locks, dogs and alarms. It is difficult to categorize the altitude of a suburb within either of these guardianship typologies. A greater altitude in an area is certainly not a social guardian, but neither is it a physical guardian; at least not according to how physical guardianship is defined in the literature (see Miethe \& Meier, 1990; Meier \& Miethe, 1993). It is plausible then that this feature of the physical landscape could be classified as a 'natural' guardian against crime and in this sense is linked to the framework proposed by defensible space theory (Newman, 1972). But in this context natural guardians refer to the physical appearance of the house and its immediate surroundings and do not refer to the shape and underlying physical properties of the land on which the residence is built. Perhaps the altitude of an area can best be classified as a topographic guardian against burglary in the sense that it characterizes the relief and terrain of the land. Whilst in a broader sense, the topography of an area can include vegetative and human-made features; these features are generally categorized as physical guardians in the literature (see Miethe \& Meier, 1990; Ratcliffe, 2003).

One notable advantage that altitude and other potential topographic guardians hold over other real or perceived social and physical guardians is that topographic guardians do not change over time or alter their appearance. Both the altitude and slope of a neighborhood for example are constant in space and time, whereas both social and physical guardians are fluid. 
People, as social guardians, are notoriously unpredictable in their movements and behavior whilst certain measures of physical guardianship such as burglar alarms could be unarmed or locks could be accidentally left unlocked. Whilst this may be trivializing things, there can be little doubt that regardless of the data utilized and methods employed researchers can rarely be sure of the current state (i.e., absence or presence) of social and physical guardians within a single household over a short period of time, let alone a whole neighborhood over a long period of time. The same cannot be said for topographic guardians as the broader features of physical geography within an area are unlikely to change, ever. Empirically speaking, the constant state of topographic guardians can allow for more detailed spatial and statistical analysis to be undertaken that can accurately assess the impact of these guardians on localized crime rates over time; this is the focus of current research.

\section{Conclusion}

There can be little doubt that the physical characteristics of an area - be they natural or man-made features - influence crime levels. This research examined the influence of two such physical geography features on crime and found that altitude does influence the spatial patterning of burglary, at least in a South African context. In doing so this finding makes an important contribution to the geography-criminology nexus as it provides, for the first time, empirical evidence that broader features of physical geography can influence the movements that burglars, and potentially other criminal offenders, are prepared to undertake. The study also provides some measure of applicability of the routine activities framework in a South African context. Whilst certainly not a central aim of the study, preliminary results suggests that the RA framework does not adequately explain burglary rates in South Africa although more work in this area is required. 
In his paper The Topography of Crime, Felson (2002) notes that understanding the role that physical geography plays in crime science is essential for building a more successful environmental criminology. It is only by examining the 'minutiae' of crime, according to Felson, that effective place-based solutions to crime can be found. It is anticipated that the results of this study examining this overlooked 'minutiae' of crime can pave the way for further research examining how broader features of physical geography guides offender movements and motivates area target selections. 


\section{References}

Armitage, R. (2007). 'Sustainability versus safety: confusion, conflict and contradiction in designing out crime.’ In G. Farrell, K. Bowers, S. D. Johnson, and M. Townsley (Eds.), Imagination for crime prevention: essays in honour of Ken Pease. Crime prevention studies (pp. 81-110). Monsey, NY and Cullompton, Devon: Criminal Justice Press and Willan Publishing.

Baumer, E., \& Wright, R. (1996). Crime seasonality and serious scholarship: a comment on Farrell and Pease. British Journal of Criminology, 36, 579-581.

Bernasco, W., \& Luykx, F. (2003). Effects of attractiveness, opportunity and accessibility to burglars on residential burglary rates of urban neighborhoods. Criminology, 41, 9811002

Bernasco, W., \& Nieuwbeerta, P. (2005). How do residential burglars select target areas? A new approach to the analysis of criminal location choice. British Journal of Criminology, 44, 296-315.

Bichler, G., Christie-Merrall, J., \& Sechrest, D. (2011). Examining juvenile delinquency within activity space: building a context for offender travel patterns. Journal of Research in Crime and Delinquency, 48, 472-506.

Bowers, K., Johnson, S. D. \& Hirschfield, A. F. G. (2004). Closing off opportunities for crime: an evaluation of alley-gating. European Journal on Criminal Policy and Research, 10, 285-308.

Brantingham, P. J., \& Brantingham, P. L. (1981). Environmental criminology. Beverly Hills: Sage.

Brantingham, P. J., \& Brantingham, P. L. (1991). Environmental criminology $2^{\text {nd }}$ ed. Prospect Heights, IL: Waveland Press. 
Brantingham, P. J., \& Brantingham, P. L. (1993). Nodes, paths and edges: considerations on the complexity of crime and the physical environment. Journal of Environmental Psychology, 13, 3-28.

Brantingham, P. L., \& Brantingham, P. J. (2000). A conceptual model for anticipating crime displacement. Paper presented at the American Society of Criminology Annual Meeting, San Francisco, CA.

Brantingham, P. L., \& Brantingham, P. J. (2003). Anticipating the displacement of crime using the principles of environmental criminology. Crime Prevention Studies, 16, 119148.

Breetzke, G. D. (2006). Geographical information systems (GIS) and policing in South Africa: a review. Policing: An International Journal of Policing Strategies and Management, 29, 723-740.

Breetzke, G. D., \& Horn, A. C. (2009). A geodemographic profiler for high offender propensity areas in the city of Tshwane, South Africa. Environment and Planning A, $41,112-127$.

Brown, B. B., \& Altman, I. (1981). Territoriality and residential crime: a conceptual framework. In P. J. Brantingham and P. L. Brantingham (Eds.), Environmental criminology (pp. 55-76). Prospect Heights, Ill: Waveland Press.

Brunsdon, C., Fotheringham, A. S., \& Charlton, M. (1998). Spatial nonstationarity and autoregressive models. Environment and Planning A, 30, 957-973.

Brunsdon, C., Corcoran, J., Higgs, G., \& Ware, A. (2009). The influence of weather on local geographical patterns of police calls for service. Environment and Planning B: Planning and Design, 36, 906-926. 
Byrne, J. M., \& Sampson, R. J. (1986). Key issues in the social ecology of crime.

In J. M. Byrne and R. J. Sampson (Eds.), The social ecology of crime (pp. 1-22). New York: Springer-Verlag.

Cahill, M. E., Mulligan, G. F. (2003). The determinants of crime in Tucson, Arizona. Urban Geography, 24, 582-610.

Cahill, M. E., Mulligan, G. F. (2007). Using geographically weighted regression to explore local crime patterns. Social Science Computer Review, 25, 174-193.

Ceccato, V. (2005). Homicide in São Paulo, Brazil: assessing spatial-temporal and weather variations. Journal of Environmental Psychology, 25, 307-321.

Ceccato, V., \& Dolmen, L. (2011). Crime in rural Sweden. Applied Geography, 31, 119-135.

Chainey, S., \& Ratcliffe, J. (2005). GIS and crime mapping. Chichester, UK: Wiley.

Clare, J., Fernandez, J., \& Morgan, F. (2009). Formal evaluation of the impact of barriers and connectors on residential burglars' macro-level offending location choices. Australian and New Zealand Journal of Criminology, 42, 139-158.

Cohen, L. E., \& Felson, M. (1979). Social change and crime rate trends: a routine activity approach. American Sociological Review, 44, 588-608.

Cohn, E. G., \& Rotton, J. (2000). Weather, seasonal trends and property crimes in Minneapolis, 1987-1988. a moderator-variable time-series analysis of routine activities. Journal of Environmental Psychology, 20, 257-272.

Cornish, D., \& Clarke, R. V. (1986). The Reasoning Criminal. New York: Springer-Verlag. Coupe, T., \& Blake, L. (2006). Daylight and darkness targeting strategies and the risks of being seen at residential burglaries. Criminology, 44, 431-464. 
Dahlbäck, O. (1998). Modelling the influence of societal factors on municipal theft rates in Sweden: methodological concerns and substantive findings. Acta Sociologica, 31, $37-$ 57.

Edney, J. J. (1972). Place and space: the effects of experience with a physical locale. Journal of Experimental Social Psychology, 8, 124-135.

Feldman, H. S., \& Jarmon, R. G. (1979). Factors influencing criminal behavior in Newark: a local study in forensic psychiatry. Journal of Forensic Science, 24, 234-239.

Felson, M. (2002). The topography of crime. Crime Prevention and Community Safety, 4, 4751.

Gao, J., \& Li, S. (2011). Detecting spatially non-stationary and scale-dependent relationships between urban landscape fragmentation and related factors using Geographically Weighted Regression. Applied Geography, 31, 292-302.

Garofalo, J., \& Clark, D. (1992). Guardianship and residential burglary. Justice Quarterly, 9, 443-463.

Graif, C., \& Sampson, R. J. (2009). Spatial heterogeneity in the effects of immigration and diversity on neighborhood homicide rates. Homicide Studies, 13, 242-260.

Hammond, L., \& Youngs, D. (2011). Decay functions and criminal spatial processes: geographical offender profiling of volume crime. Journal of Investigative Psychology and Offender Profiling, 8, 90-102.

Harries, K. (2006). Property crimes and violence in the United States: an analysis of the influence of population density. International Journal of Criminal Justice Sciences, 1, 24-34. 
Heller, N. B., \& Markland, R. E. (1970). A climatological model for forecasting the demand for police service. Journal of Research in Crime and Delinquency, 7, 167-176.

Herbert, D. T., \& Harries, K. D. (1986). Area-based policies for crime prevention. Applied Geography, 6, 281-295.

Huang, Y., \& Leung, Y. (2002). Analyzing regional industrialization in Jiangsu Province using geographically weighted regression. Journal of Geographical Systems, 4, 233 249.

Jacob, J. C. (2006). Male and female youth crime in Canadian communities: assessing the applicability of social disorganization theory. Canadian Journal of Criminology and Criminal Justice, 48, 31-60.

Johnson, S. D., \& Bowers, K. (2010). Permeability and burglary risk: are cul-de-sacs safer? Journal of Quantitative Criminology, 26, 89-111.

Kuo, F. E., \& Sullivan, W. C. (2001). Environment and crime in the inner city: does vegetation reduce crime? Environment and Behavior, 33, 343-367.

Landau, S. F., \& Fridman, D. (1993). The seasonality of violent crime: the case of robbery and homicide in Israel. Journal of Research in Crime and Delinquency, 30, 163-191.

Landman, K., \& Schönteich, M. (2002). Urban fortresses: gated communities as a reaction to crime. African Security Review, 11, 71-85.

Lee, S-II. (2004). Spatial data analysis for the US regional income convergence, 1969-1999: a critical appraisal of b-convergence. Journal of the Korean Geographical Society, 39, 212-228. 
Martino, D. (2008). Gender and urban perceptions of nature and protected areas in Bañados del Este biosphere reserve. Environmental Management, 41, 654-662.

McDowall, D., \& Loftin, C. (1992). Comparing the UCR and NCS over time. Criminology, $30,125-132$.

Meier, R. F., \& Miethe, T. D. (1993). Understanding theories of criminal victimization. In M. Tonry (Ed.), Crime and justice: a review of research (pp. 459-499). Chicago, IL: University of Chicago Press.

Miethe, T. D., \& Meier, R. F. (1990). Opportunity, choice, and criminal victimization: a test of a theoretical model. Journal of Research in Crime and Delinquency, 27, 243-266.

Miethe, T. D., \& Meier, R. F. (1994). Crime and its social context: toward an integrated theory of offenders, victims, and situations. Albany: State University of New York Press.

National Spatial Development Perspective (2006). Chief police analyst, published by The Presidency, Republic of South Africa.

Newman, O. (1972). Defensible space: crime prevention through urban design. New York: Macmillan.

Peeters, M. P., \& Elffers, H. (2010). Do physical barriers affect urban crime trips? Crime Patterns and Analysis, 3, 38-49.

Perry, J. D., \& Simpson, M. E. (1987). Violent crimes in a city: environmental determinants. Environment and Behavior, 19, 77-90.

Proffitt, D. R., Bhalla, M., Gossweiler, R., \& Midgett, J. (1995). Perceiving geographical slant. Psychonomic Bulletin \& Review, 2, 409-428 
Ratcliffe, J. H. (2003). Suburb boundaries and residential burglars (No. 246). Canberra, Australia: Australian Institute of Criminology.

Rengert, G. F., Piquero, A. R., \& Jones, P. R. (1999). Distance decay re-examined. Criminology, 37, 427-43.

Rice, K. J., \& Smith, W. R. (2002). Socioecological models of automotive theft: integrating routine activity and social disorganization approaches. Journal of Research in Crime and Delinquency, 39, 304-336.

Richards, P. (1974). Kant's geography and mental maps. Transactions of the Institute of British Geographers, 61, 1-16.

Rotton, J., \& Frey, J. (1985). Air pollution, weather, and violent crimes: concomitant timeseries analysis of archival data. Journal of Personality and Social Psychology, 49, 1207-1220.

Sampson, R. J., \& Wooldredge, J. D. (1987). Linking the micro- and macro-level dimensions of lifestyle-routine activity and oppotunity models of predatory victimization. Journal of Quantitative Criminology, 3, 371-393.

Sampson, R. J., \& Groves, W. B. (1989). Community structure and crime: testing social disorganization theory. American Journal of Sociology, 94, 774-802.

Schönteich, M., \& Louw, A. (2001). Crime in South Africa: a country and cities profile. Institute for Security Studies Paper 49, April 2001.

Shaw, C., \& McKay, H. D. (1942). Juvenile delinquency and urban areas. Chicago: University of Chicago Press.

Snook, B. (2004). Individual differences in distance travelled by serial burglars.' Journal of Investigative Psychology and Offender Profiling, 1, 53-66. 
Stefanucci, J. K., Proffitt, D. R., Clore, G. L., \& Parekh, N. (2008). Skating down a steeper slope: Fear influences the perception of geographical slant. Perception, 37, 321-323.

Stefanucci, J. K., Proffitt, D. R. 92009). The roles of altitude and fear in the perception of height. Journal of Experimental Psychology: Human Perception and Performance, 35, 424-438.

Turvey, B. E. (2008). Criminal profiling: an introduction to behavioral analysis $\left(3^{\text {rd }}\right)$ edition. Academic Press.

United Nations Development Program. (2003). South Africa Human Development Report 2003. Cape Town, South Africa: Oxford University Press.

Van Koppen, P. J., \& and de Keijser, J. W. (1997). Desisting distance decay: on the aggregation of individual crime trips. Criminology, 35, 505-515.

Van Koppen, P. J., \& Jansen, R. W. (1999). The time to rob: variation in time of number of commercial robberies. Journal of Research on Crime and Delinquency, 36, 7-29.

Vélez, M. B. (2001). The role of public social control in urban neighbourhoods: a multi-level analysis of victimization risk. Criminology, 39, 837-864.

Wyant, B. R. (2008). Multilevel impacts of perceived incivilities and perceptions of crime risk on fear of crime: isolating endogenous impacts. Journal of Research in Crime and Delinquency, 45, 39-64.

Zhang, L., Messner, S. F., \& Liu, J. (2007). A multilevel analysis of the risk of household burglary in the city of Tianjin, China. British Journal of Criminology, 47, 918-937.

Zinn, R. (2008). The incidence of house robberies in South Africa. Unpublished Doctoral Thesis, University of South Africa (UNISA), South Africa. 
Zipf, G. K. (1949). Human behavior and the principle of least effort: An introduction to human ecology. Cambridge, MA: Addison-Wesley Press. 